\title{
An update on the neuropsychiatric complications of COVID-19
}

\author{
Ioannis Mavroudis, Eleni Karantali, Symela Chatzikonstantinou, \\ Florin Petriş, Alin Ciobîcă, Adrian Cantemir, Dimitrios Kazis
}

\begin{abstract}
Ioannis Mavroudis - PhD, Neurology Department, Leeds Teaching Hospitals, NHS Trust, Leeds, UK

Eleni Karantali - PhD, Third Department of Neurology, Aristotle University of Thessaloniki, Greece

Symela Chatzikonstantinou - PhD, Third Department of Neurology, Aristotle University of Thessaloniki, Greece
\end{abstract}

Alin Ciobîcă - PhD, Faculty of Biology, "Alexandru Ioan Cuza” Iaşi University, Romania, Academy of Romanian Scientists, Bucureşti, Center of Biomedical Research, Romanian Academy, Iaşi

Adrian Cantemir - MD, PhD, assistant of professor, "Grigore T. Popa" University of Medicine and Pharmacy Iași, Romania

Florin Petriș - MD, PhD, professor, "Grigore T. Popa” University of Medicine and Pharmacy Iași, Romania

Dimitrios Kazis - $\mathrm{PhD}$, professor, Third Department of Neurology, Aristotle University of Thessaloniki, Greece

\section{ABSTRACT}

SARS-CoV-2 is a single-stranded RNA coronavirus predominantly causes a respiratory disease, however increasing evidence has shown that it is also related to several neurological complications. The underlying mechanisms of SARS-CoV-2 neurotropic action is not yet clearly understood; however, it is believed that the virus can enter the central nervous system either through the haematogenous route, or through neuronal anterograde dissemination. The main neurological manifestations of patients positive for SARS-CoV-2 can be categorized to parainfectious, post-infectious and cerebrovascular complications. In the present study we describe the main neurological complications as they have been described in the most recent literature.

KEYWORDS:

COVID-19, SARS-CoV-2, neuropsychiatric manifestations. 


\section{INTRODUCTION}

SARS-CoV-2 is a single-stranded RNA coronavirus that has been classified at the genus of Betacoronavirus, subgenus Sarbecovirus and is the seventh member of the coronavirus family that can infect humans $(1,2)$. SARS-CoV-2 causes a respiratory illness; however, increasing evidence has shown that it is also related to a number of neurological complications. The underlying pathophysiological mechanisms of SARS$\mathrm{CoV}-2$ related neurological manifestations are not yet clearly understood, however having other viruses' neurotropic mechanisms as a reference, there are two main routes that a virus can enter the central nervous system (CNS), the hematogenous and the neuronal retrograde dissemination $(3,4,5)$. It is thought that SARS-CoV-2 infects endothelial cells of the blood-brain-barrier, allowing direct passage into the CNS (6). In addition to that, it has been found that the virus can infect monocytes and macrophages to migrate through the blood-brain-barrier (7). Another major route is thought to be the peripheral or cranial nerves, while SARS-CoV-2 can use axonal transportation to enter the CNS (3 -5).

Experimental evidence has shown that SARSCoV-2 enters the brain of hACE2 mice through the olfactory bulb, resulting in rapid, transneuronal spread to related areas of the brain (8). Furthermore, multiple reports have shown that the virus can affect the CNS indirectly by triggering a cytokine storm, which can result in a BBB breakdown without direct viral invasion, and can be responsible for an acute necrotizing encephalopathy or polyradiculopathy $(9-12)$.

\section{NEUROLOGICAL COMPLICATIONS Encephalitis}

The term encephalitis usually describes an immune-mediated inflammation of the brain parenchyma. It is characterized by pleocytosis in the cerebrospinal fluid (CSF), focal abnormalities in the electroencephalogram (EEG), and certain neuroimaging findings. Since the beginning of the COVID-19 pandemic, there are several cases of COVID19 related encephalitis. Their neurological symptoms started up to 17 days after the respiratory illness, and in at least one of the cases, neurological symptoms preceded the respiratory ones (13). Amongst clinical symptoms, irritability, confusion and reduced consciousness, occasional seizures, neck stiffness, psychotic symptoms, ataxia, oscillopsia, hiccups, and bilateral facial palsy were the more frequent (14-17). The CSF showed pleocytosis, mainly lymphocytic, but was normal in at least one case. Brain imaging was normal in most cases, but in the minority of cases, it showed high signal lesions in the temporal lobe, the cerebellum, and into spinal cord (15). EEG showed generalized slowing, focal abnormalities, and on one occasion, non-convulsive status epilepticus (16-19). Although there is no specific treatment for COVD-19 encephalitis, corticosteroids might be useful.

\section{Encephalopathies}

A retrospective study from Wuhan, China, in 214 patients with COVID-19, described symptoms from the central nervous symptoms in $25 \%$ of them, including dizziness (17\%), headache $(13 \%)$, and impaired consciousness (7\%) (20). Another series from France on 58 patients with COVID-19 described neurological complications in $84 \%$ of patients in intensive care, including encephalopathy (67\%) with corticospinal tract signs. CSF showed no pleocytosis in a small percentage of patients. About one-third of patients (33\%) had a dysexecutive syndrome (21). Further cases of necrotizing encephalopathy and a fatal case with viral particles in endothelial 
cells and neural tissue have been described (21). Children with COVID-19 have developed seizures, with paroxysmal episodes consistent with seizures in two infants with no respiratory symptoms but positive SARSCoV-2 nasopharyngeal swab (22, 23). A small percentage of children hospitalized with COVID-19 also developed seizures (23).

\section{Parainfectious encephalopathy with psychosis}

Paterson et al. described a case of a 55-yearold female patient without a previous history of neurological or psychiatric issues who was admitted with fever, cough, muscle aches, breathlessness, anosmia, and hypogeusia. The patient required minimal oxygen treatment and was discharged three days later, but the following day she developed confusion and odd behavior, with disorientation. She described visual hallucinations and developed auditory hallucinations, persecutory delusions, and a Capgras type psychotic episode. Her brain MRI, EEG, and lumbar puncture were normal, and her clinical course improved with haloperidol, followed by risperidone (24).

\section{Acute disseminated encephalomyelitis and myelitis}

ADEM typically occurs after an infection and presents with focal neurological symptoms, usually encephalopathy and multifocal degeneration (25). Two case reports in middle-aged women with positive SARSCoV-2 swabs who developed acute disseminated encephalomyelitis have been described so far $(26,27)$. Amongst the symptoms, dysphagia, dysarthria, and encephalopathy were the most common ones (27), while seizures with reduced consciousness, headaches, and myalgia were also described (28). Both patients had normal CSF and typical findings on MRI for ADEM. They improved with intravenous immunoglobulin and steroids. A case of myelitis in a man aged 66 years in Wuhan, China, has also been described with fever, fatigue, acute flaccid paraparesis, and incontinence. His neurological examination revealed hyporeflexia and sensory level at T10, and the patient was treated with dexamethasone, intravenous immunoglobulin, and was discharged with rehabilitation (28).

Paterson et al. also described a case of ADEM with hemorrhage in a critically ill patient and a case of the acute hemorrhagic leukoencephalopathy form of ADEM in a 47year-old patient that required decompressed craniotomy (24).

\section{Peripheral nervous system}

A number of patients with Guillain-Barre syndrome (GBS) or its variants and COVID19 have been reported (25). The main neurological symptoms started around seven days after the respiratory symptoms, and some patients also developed febrile illness seven days after the onset of $\operatorname{GBS}(29,30)$. The majority of patients developed weakness of all four limbs with or without sensory loss (30-35), while a small number of patients developed the paraparetic variant with leg weakness only $(29,32,36)$, lower limb paresthesia facial nerve involvement, dysphagia, respiratory failure, and autonomic nervous system complications (32). Neurophysiology showed demyelinating disease in the majority of cases and axonal in about 30\%. Case reports with the MillerFisher variant, with ophthalmoplegia, ataxia, and areflexia, have also been described (37, 38), while a case of an acute vestibular syndrome with horizontal nystagmus and oscillopsia has been reported (39). Lumbar puncture showed albuminocytological dissociation in most patients. Patients were treated with IVIG, and some of them required ventilatory support $(34,35)$. 


\section{Headaches}

Huang et al., in an early study in 41 SARSCoV-2 positive patients in Wuhan, China, described non-specific headaches in $8 \%$ of patients (40).

\section{Muscle pathology}

Myopathy with raised creatinekinase and rhabdomyolysis has been described in $11 \%$ of patients in the Wuhan series (41).

\section{Olfactory dysfunction and hypogeusia}

Olfactory dysfunction, anosmia, and ageusia have been described in most patients with COVID-19 (82-86\%) (42, 43), and they are the most common self-reported initial symptoms amongst patients $(44,45)$. A neuropathological study of human olfactory bulb tissues infected with SA|RS-CoV2 did not reveal viral infection or injury to the neural tissue (46). These are thought to be related to epithelial damage (47).

\section{Tremor and ataxia}

Diezma-Martín et al. have described a case of parainfectious ataxia with marked bilateral action and postural tremor in a 70 years old patient with a previous history of COPD but no additional symptoms. The patient developed progressive tremor on all four limbs, voice tremor, and an orthostatic element. Brain MRI and lumbar puncture were normal. The patient was treated with clonazepam with slight improvement (48).

\section{Cerebrovascular complications}

Cerebrovascular complications of COVID-19 have been reported for $6 \%$ of patients in
Wuhan series, including ischemic stroke $(5 \%)$, intracerebral hemorrhage $(1 \%)$, and cerebral sinus \%venous thrombosis (1\%). Another retrospective study in Italy reported that $2 \%$ of patients who were admitted to neurology with laboratory-confirmed SARSCoV-2 had a cerebrovascular event, including ischemic stroke, hemorrhagic stroke, and transient ischemic attacks (49). Other studies also described cerebrovascular events in relation to COVID-19 infection in small percentages of patients (2\%) (50). The majority of cerebrovascular events includes ischemic events, and hemorrhagic incidents concern only a small percentage of patients. Most patients were older than 60 years and also had known risk factors for cerebrovascular disease; however, younger stroke patients have also been described (51, 52). Cerebrovascular symptoms started about 10 (0-33) days after the onset of the respiratory illness. In one case, the stroke preceded respiratory symptoms, and a small number of patients had only cerebrovascular symptoms with no respiratory illness (52-55). The most common laboratory findings for these patients include raised blood D-dimer, positive lupus anticoagulant, anticardiolipin, and anti- $\beta 2$-glycoprotein- 1 antibodies (56).

CODIV-19 is known to increase the risk of thrombotic episodes, hence immediate anticoagulation with low-molecular-weight heparin has been recommended (57); however, this approach should always be balanced against the risk of intracranial hemorrhage.

\section{DISCUSSION}

COVID-19 is manifested by several symptoms, ranging from asymptomatic/mild symptoms to severe illness and death. It is mainly linked to respiratory symptoms and complications; however multiple studies since the beginning of the pandemic have reported certain neurological complications, including encephalitis, encephalopathy, anosmia and ageusia, headaches, acute disseminating encephalomyelitis, cerebrovascular events, and Guillain-Barre syndrome. The 

underlying neurotropic mechanisms of SARS-CoV-2 are not yet clearly understood; however, it is thought that there are two main routes for the virus to enter the CNS, haematogenous, or through the peripheral nerves. The percentage of neurological patients is small compared to respiratory system illness; however, given that the pandemic is currently one the second wave, more patients will present neurological complications. Additional evidence will give new insights into our understanding of SARS-CoV-2 mechanisms and related diseases and conditions.

\section{ACKNOWLEDGEMENTS AND DISCLOSURES}

The authors state that there are no declared conflicts of interest regarding this paper.

\section{REFERENCES}

1. Lu R, Zhao X, Li J, Niu P, et al. Genomic characterisation and epidemiology of 2019 novel coronavirus: implications for virus origins and receptor binding. Lancet. 2020;395(10224):565-574.

2. Zhu N, Zhang D, Wang W, et al. A novel Coronavirus from patients with pneumonia in China, 2019. N Engl J Med. 2020;382(8):727-733.

3. Desforges M, Le Coupanec A, Dubeau P, Bourgouin A, Lajoie L, Dube M, Talbot PJ. Human Coronaviruses and other respiratory viruses: underestimated opportunistic pathogens of the central nervous system? Viruses. 2019.

4. Wanson PA, Mc Gavern DB. Viral diseases of the central nervous system. Curr Opin Virol. 2015;11:44-54.

5. Desforges M, Le Coupanec A, Stodola JK, Meessen-Pinard M, Talbot PJ. Human coronaviruses: viral and cellular factors involved in neuroinvasiveness and neuropathogenesis. Virus Res. 2014;194:145-158.

6. Guo Y, Korteweg C, McNutt MA, Gu J. Pathogenetic mechanisms of severe acute respiratory syndrome. Virus Res. 2008;133(1):4-12.

7. $\mathrm{Gu} \mathrm{J}$, Gong E, Zhang B, et al. Multiple organ infection and the pathogenesis of SARS. J Exp Med. 2005;202(3):415-424.

8. Netland J, Meyerholz DK, Moore S, Cassell M, Perlman S. Severe acute respiratory syndrome coronavirus infection causes neuronal death in the absence of encephalitis in mice transgenic for human ACE2. J Virol. 2008;82(15):7264-7275.

9. Poyiadji N, Shahin G, Noujaim D, Stone M, Patel S, Griffith B. COVID-19-associated acute hemorrhagic necrotizing encephalopathy: CT and MRI features. Radiology. 2020.

10. Zhao H, Shen D, Zhou H, Liu J, Chen S. Guillain-Barre syndrome associated with SARS-CoV-2 infection: causality or coincidence? Lancet Neurol. 2020;19(5):383-384.

11. Mehta P, McAuley DF, Brown M, Sanchez E, Tattersall RS, Manson JJ, H1h Across Speciality Collaboration UK COVID-19: consider cytokine storm syndromes and immunosuppression. Lancet. 2020;395(10229):1033-1034. doi: 10.1016/S0140-6736(20)30628-0.

12. Zhang Y, Xiao M, Zhang S, et al. Coagulopathy and antiphospholipid antibodies in patients with Covid-19. N Engl J Med. 2020;382(17):e38.

13. Duong L Xu P Liu A Meningoencephalitis without respiratory failure in a young female patient with COVID-19 infection in downtown Los Angeles, early April 2020. Brain Behav Immun. 2020.

14. Moriguchi T Harii N Goto J et al. A first case of meningitis/encephalitis associated with SARS-coronavirus-2. Int J Infect Dis. 2020; 94: 55-58.

15. Paniz-Mondolfi A Bryce $\mathrm{C}$ Grimes $\mathrm{Z}$ et al. Central nervous system involvement by severe acute respiratory syndrome coronavirus-2 (SARS-CoV-2). J Med Virol. 2020; 92: 699-702.

16. Duong L Xu P Liu A Meningoencephalitis without respiratory failure in a young female patient with COVID-19 infection in downtown Los Angeles, early April 2020. Brain Behav Immun. 2020.

17. Bernard-Valnet R Pizzarotti B Anichini A et al. Two patients with acute meningo-encephalitis concomitant to SARS-CoV-2 infection. Eur J Neurol. 2020.

18. Sohal S Mossammat M COVID-19 presenting with seizures. IDCases. 2020; 20e00782

19. Vollono C Rollo E Romozzi M et al. Focal status epilepticus as unique clinical feature of COVID-19: a case report. Seizure. 2020; 78: 109-112.

20. Mao L, Jin H, Wang M et al. Neurologic manifestations of hospitalized patients with coronavirus disease 2019 in Wuhan, China. JAMA Neurol. 2020.

21. Paniz-Mondolfi A Bryce C Grimes $\mathrm{Z}$ et al. Central nervous system involvement by severe acute respiratory syndrome coronavirus-2 (SARS-CoV-2). J Med Virol. 2020; 92: 699-702

22. Dugue R Cay-Martínez KC Thakur KT et al. Neurologic manifestations in an infant with COVID-19. Neurology. 2020.

23. Chacón-Aguilar R Osorio-Cámara JM Sanjurjo-Jimenez I González-González C López-Carnero J Pérez-MoneoAgapito B COVID-19: fever syndrome and neurological symptoms in a neonate. An Pediatr. 2020. 
(0) 24. Paterson RW, Brown RL, Benjamin Let al The emerging spectrum of COVID-19 neurology: clinical, radiological and laboratory findings. Brain. 2020 Oct 1;143(10):3104-3120. doi: 10.1093/brain/awaa240. PMID: 32637987; PMCID: PMC7454352.

25. Willison HJ Jacobs BC van Doorn PA Guillain-Barré syndrome. Lancet. 2016; 388: 717-727

26. Zanin L Saraceno G Panciani PP et al. SARS-CoV-2 can induce brain and spine demyelinating lesions. Acta Neurochir (Wien). 2020; (https://doi.org.10.1007/s00701-020-

27. Zhang T Rodricks MB Hirsh E COVID-19-associated acute disseminated encephalomyelitis: a case report. medRxiv. 2020.

28. Zhao K Huang J Dai D Feng Y Liu L Nie S Acute myelitis after SARS-CoV-2 infection: a case report. medRxiv. 2020 .

29. Abdelnour L Eltahir Abdalla M Babiker S COVID 19 infection presenting as motor peripheral neuropathy. J Formos Med Assoc. 2020; 119: 1119-1120.

30. Zhao H Shen D Zhou H Liu J Chen S Guillain-Barre syndrome associated with SARS-CoV-2 infection: causality or coincidence?. Lancet Neurol. 2020; 19: 383-384.

31. Camdessanche J-P Morel J Pozzetto B Paul S Tholance Y Botelho-Nevers E COVID-19 may induce GuillainBarré syndrome. Rev Neurol. 2020; 176: 516-518

32. Toscano G Palmerini F Ravaglia S et al. Guillain-Barré syndrome associated with SARS-CoV-2. N Engl J Med. 2020.

33. Galán AV del Saz Saucedo P Postigo FP Paniagua EB Guillain-Barré syndrome associated with SARS-CoV-2 infection. Neurologia. 2020; 35: 268-269.

34. Marta-Enguita J Rubio-Baines I Gastón-Zubimendi I Fatal Guillain-Barre syndrome after infection with SARSCoV-2. Neurologia. 2020; 35: 265-267.

35. Alberti P Beretta S Piatti M et al. Guillain-Barré syndrome related to COVID-19 infection. Neurol Neuroimmunol Neuroinflamm. 2020; 7: e741.

36. Coen M Jeanson G Culebras Almeida LA et al. Guillain-Barré syndrome as a complication of SARS-CoV-2 infection. Brain Behav Immun. 2020.

37. Gutiérrez-Ortiz C Méndez A Rodrigo-Rey S et al. Miller Fisher Syndrome and polyneuritis cranialis in COVID19. Neurology. 2020.

38. Dinkin M Gao V Kahan J et al. COVID-19 presenting with ophthalmoparesis from cranial nerve palsy. Neurology. 2020.

39. Escalada Pellitero S Garriga Ferrer-Bergua L Report of a patient with neurological symptoms as the sole manifestation of SARS-CoV-2 infection. Neurologia. 2020; 35: 271.

40. Huang C, Wang Y, Li X, et al. Clinical features of patients infected with 2019 novel coronavirus in Wuhan, China (published correction appears in Lancet. 2020 Jan 30;:). Lancet. 2020;395(10223):497-506.

41. Jin M Tong Q Rhabdomyolysis as potential late complication associated with COVID-19. Emerg Infect Dis. 2020.

42. Moein ST Hashemian SMR Mansourafshar B Khorram-Tousi A Tabarsi P Doty RL Smell dysfunction: a biomarker for COVID-19. Int Forum Allergy Rhinol. 2020.

43. Hornuss D Lange B Schröter N Rieg S Kern WV Wagner D Anosmia in COVID-19 patients. Clin Microbiol Infect. 2020.

44. Menni C, Valdes AM, Freidin MB, Sudre CH, Nguyen LH, Drew DA, Ganesh S, Varsavsky T, Jorje Cardoso M, El-Sayed Mustafa JS, Visconti A, Pirro H, Bowyer RC, Mangino M, Falchi M, Wolfe J, Ourselin S, Chan AT, Steves CJ, Spector TD. Real-time tracking of self-reported symptoms to predict potential COVID-19. Nat Med. 2020;26:10371040 .

45. Cooper KW, Brann DH, Farruggia MC, Bhutani S, Pellegrino R, Tsukahara T, Weinreb C, Joseph PV, Larson ED, Parma V, Albers MW, Barlow LA, Datta SR, Di Pizio A (2020) COVID-19 and the chemical senses: supporting players take center stage. Neuron. S0896-6273(20)30486-4. 10.1016/j.neuron.2020.06.032

46. Solomon IH, Normandin E, Mukerji SS, Keller K, Ali A, Adams G, Hornick J, Sabeti P (2020b) Neuropathological features of Covid-19. NEJM. 10.1056/NEJMc2019373.

47. Azizi SA, Azizi SA. Neurological injuries in COVID-19 patients: direct viral invasion or a bystander injury after infection of epithelial/endothelial cells. J Neurovirol. 2020;26(5):631-641.

48. Diezma-Martín AM, Morales-Casado MI, García-Alvarado N, Vadillo Bermejo A, López-Ariztegui N, Sepúlveda Berrocal MA. Tremor and ataxia in COVID-19. Tremor and ataxia in COVID-19. Neurology . 2020; 35 (6): $409-410$.

49. Benussi A Pilotto A Premi E et al. Clinical characteristics and outcomes of inpatients with neurologic disease and COVID-19 in Brescia, Lombardy, Italy. Neurology. 2020.

50. Klok FA Kruip MJHA van der Meer NJM et al. Incidence of thrombotic complications in critically ill ICU patients with COVID-19. Thromb Res. 2020; 191: 145-147.

51. Beyrouti R Adams ME Benjamin L et al. Characteristics of ischaemic stroke associated with COVID-19. J Neurol Neurosurg Psychiatry. 2020.

52. Oxley TJ Mocco J Majidi S et al. Large-vessel stroke as a presenting feature of Covid-19 in the young. N Engl J Med. 2020; 382: e60

53. Avula A Nalleballe K Narula N et al. COVID-19 presenting as stroke. Brain Behav Immun. 2020. 

54. Al Saiegh F Ghosh R Leibold A et al. Status of SARS-CoV-2 in cerebrospinal fluid of patients with COVID-19 and stroke. J Neurol Neurosurg Psychiatry. 2020.

55. González-Pinto T Luna-Rodríguez A Moreno-Estébanez A Agirre-Beitia G Rodríguez-Antigüedad A Ruiz-Lopez M Emergency room neurology in times of COVID-19: malignant ischaemic stroke and SARS-CoV-2 infection. Eur J Neurol. 2020.

56. Zhang Y Xiao M Zhang S et al. Coagulopathy and antiphospholipid antibodies in patients with Covid-19. N Engl J Med. 2020; 382: e38

57. Thachil $\mathrm{J}$ Tang $\mathrm{N}$ Gando $\mathrm{S}$ et al. ISTH interim guidance on recognition and management of coagulopathy in COVID-19. J Thromb Haemost. 2020; 18: 1023-1026

\section{Correspondence:}

Ioannis Mavroudis,

PhD, Neurology Department, Leeds Teaching Hospitals, NHS Trust, Leeds, United Kingdom, i.mavroudis@nhs.net 